\title{
New strategy to rescue the inhibition of osteogenesis of human bone marrow-derived mesenchymal stem cells under oxidative stress: combination of vitamin $\mathrm{C}$ and graphene foams
}

\author{
Zubin Zhou ${ }^{1, *}$, Zhengliang Xu ${ }^{1, *}$, Feng Wang ${ }^{1}$, Ye Lu ${ }^{1}$, Peipei Yin ${ }^{1}$, Chaolai Jiang ${ }^{1}$, \\ Yingjie Liu ${ }^{1}$, Hua $\mathbf{L i}^{2}$, Xiaowei Yu${ }^{1}$, Yuqiang Sun ${ }^{1}$ \\ ${ }^{1}$ Department of Orthopaedic Surgery, Shanghai Jiao Tong University Affiliated Sixth People's Hospital, Shanghai 200233, \\ China \\ ${ }^{2}$ State Key Laboratory of Metal Matrix Composites, School of Materials Science and Engineering, Shanghai Jiao Tong \\ University, Shanghai 200240, China \\ "These authors contributed equally to this work
}

Correspondence to: Xiaowei Yu, email: yuxw@sjtu.edu.cn Yuqiang Sun, email: sunyq@21cn.net

Keywords: osteogenesis, mesenchymal stem cell, oxidative stress, vitamin C, graphene foams

Received: July 18, 2016

Accepted: September 29, 2016

Published: October 04, 2016

\section{ABSTRACT}

To rescue the oxidative stress induced inhibition of osteogenesis, vitamin C (VC) was chemically modified onto three-dimensional graphene foams (3D GFs), then their regulation on osteogenesis of human bone marrow-derived mesenchymal stem cells (BM-MSCs) was studied. Combined action of VC + GF significantly decreased $\mathrm{H}_{2} \mathrm{O}_{2}-$ induced oxidative stress, and rescued $\mathrm{H}_{2} \mathrm{O}_{2}$-inhibited cell viability, differentiation and osteogenesis of BM-MSCs in vitro. Further studies revealed that Wnt pathway may be involved in this protection of osteogenesis. Furthermore, an in vivo mouse model of BM-MSCs transplantation showed that VC + GF remarkably rescued oxidative stress inhibited calcium content and bone formation. The combination of VC and GF exhibited more pronounced protective effects against oxidative stress induced inhibition of osteogenesis, compared to monotherapy of VC or GF. Our study proposed a new strategy in stem cell-based therapies for treating bone diseases.

\section{INTRODUCTION}

The homeostasis of human bones is tightly balanced by the orchestrated activities of bone-forming osteoblasts and bone-resorbing osteoclasts. Oxidative stress, resulted from excessive reactive oxygen species (ROS) production, disrupts the homeostasis by inhibiting osteoblast function and stimulating osteoclastogenesis [1]. Chronic exposure of oxidative stress may cause bone impairments and diseases [2]. Also, oxidative stress was reported to be a major contributing factor of osteoporosis during aging $[3,4]$. At the molecular level, ROS, including superoxide anion, hydroxyl radical, hydroxyl ion, nitric oxide (NO) and hydrogen peroxide, react with DNA, protein and lipids inside cells, which further induces cytokine-mediated pro-inflammation. Meanwhile, excessive ROS are able to react with NO forming peroxynitrite that in turn could oxidize tetrahydrobiopterin, a cofactor of endothelial nitric oxide synthase (eNOS), and result in its decoupling from eNOS, leading to further elevated ROS, as well as decreased NO productions.

Mesenchymal stem cells (MSCs) are favorable candidates for regenerative medicine and tissue engineering in the clinical management of bone-related diseases. MSCs can undergo differentiation and give rise to various other cell types, including osteoblasts, muscle cells, chondrocytes and adipocytes [5-8]. Bone marrowderived mesenchymal stem cells (BM-MSCs) exhibit high differentiating potential into the osteoblast lineage [9], which can be potentially used for cell transplantation during clinical treatment of bone diseases. In an earlier clinical trial, the therapeutic potential of BM-MSCs was clearly demonstrated in children suffering from osteogenesis imperfecta [10].

In living organisms, vitamin $\mathrm{C}(\mathrm{VC})$ is a potent reducing reagent, which is able to quickly scavenge various ROS. VC has been studied for the treatment 
of different bone diseases [11-14]. Three dimensional graphene foams (3D GFs) is a new type of nanomaterial, and its unique physical and chemical properties have sparked increasing interests since its discovery in 2004 [15]. It was reported that graphene-based materials may serve as a free radical scavenger to reduce oxidative stress in tissue engineering [16-18], which may be associated with the $\mathrm{sp}^{2}$-carbon network in these graphene materials.

In our current study, we aimed to develop a new strategy using MSC-based stem cell therapy for bone diseases, by combining VC and 3D GFs. The effect of the new strategy was examined both in in vitro cell culture and in vivo animal models.

\section{RESULTS}

\section{Modification of GFs with VC}

As illustrated in Figure 1A, GFs were exposed with $\mathrm{O}_{2}$ plasma and sequentially modified with $\mathrm{VC}$. The contact angle of pristine graphene film was approximately $76^{\circ} \mathrm{C}$, which decreased to $36^{\circ} \mathrm{C}$ after $\mathrm{O}_{2}$ plasma treatment (Figure 1B). The increased wettability of graphene with $\mathrm{O}_{2}$ plasma exposure was ascribed to the introduction of functional groups containing oxygen [25]. VC is a widely used biocompatible agent to reduce graphene oxide [26-29]. Hence, the content of functional groups containing oxygen on the surface of graphene was decreased, resulting in a slightly increased contact angle.

To clarify the structure change of graphene, Raman spectroscopy was employed to characterize the graphene and its derivatives. Figure $2 \mathrm{~A}$ shows the development of Raman spectrum exposed to $\mathrm{O}_{2}$ plasma and $\mathrm{VC}$ modification. The Raman spectrum from pristine graphene indicated that graphene had the few-layered structure. A weak D peak associated with disorder was observed, showing excellent uniformity in the sample of pristine graphene. Exposing the $\mathrm{O}_{2}$ plasma for $100 \mathrm{~s}$ has made the $\mathrm{D}$ peak react strongly at approximately $1340 / \mathrm{cm}$ (Figure 2B). With increasing exposure time, the Raman spectrum showed systematic developments in position and peak intensity $(I)$ until exposure of $600 \mathrm{~s}$ (Figure 2C), where the intensity of $\mathrm{D}$ and $\mathrm{G}$ were tremendously decreased and the $2 \mathrm{D}$ peak disappeared compared to background signals. We hereby define the peak intensity as the peak height. The Raman spectrum probes sites of $\mathrm{sp}^{2}$ through excitation of $\pi-\pi$ stacking, and amorphous carbon atom with bonding of $\mathrm{sp}^{3}$ generates weaker spectrum $[30]$. I(D)/I(G) can then be used to evaluate the degree of disorder related to the crystalline cluster diameter of the graphene nanosheet [31]. Hence, as shown in Figure 2D, in $\mathrm{O}_{2}$ plasma exposed graphene, $\mathrm{I}(\mathrm{D}) / \mathrm{I}(\mathrm{G})$ was increased with longer exposure time, indicating a reduction in the $\mathrm{sp}^{2}$ ordered ring number. In contrast, $\mathrm{I}(\mathrm{D}) / \mathrm{I}(\mathrm{G})$ declined after VC modification, which demonstrated the disordered $\mathrm{sp}^{3}$ bonding was partially reduced to $\mathrm{sp}^{2}$ state with the introduction of $\mathrm{VC}$ molecules.
Detailed compositional analysis of VC-modified $\mathrm{GF}$ was conducted and compared with pure $\mathrm{VC}$ and $\mathrm{O}_{2}$ plasma-treated GF by X-ray photo-electron spectroscopy (XPS) (Supplementary Figure S1). The XPS of GF displayed 4 different carbon bonds: $\mathrm{sp}^{2}$ carbon in $\mathrm{C}-\mathrm{C}$ (284.9 eV , carbon in $\mathrm{C}-\mathrm{O}(285.8 \mathrm{eV})$, carbonyl carbon in $\mathrm{C}=\mathrm{O}(287.6 \mathrm{eV})$, as well as carboxylate carbon in $\mathrm{C}(\mathrm{O})=\mathrm{O}(288.7 \mathrm{eV})$. After GF was modified and reduced with VC, the peak of C-C at $284.4 \mathrm{eV}$ was tremendously enhanced, whereas the oxidized carbon species peaks were decreased. In addition, the relatively strong signals at $285.6 \mathrm{eV}$ and $287.3 \mathrm{eV}$ were contributed by the $\mathrm{C}=\mathrm{O}$ and $\mathrm{C}-\mathrm{O}$ of $\mathrm{VC}$, suggesting successful immobilization of $\mathrm{VC}$ molecules onto the graphene.

\section{Human BM-MSCs growth under different conditions}

Human BM-MSCs were isolated, exhibiting their typical MSC spindle-shape (Figure 3A). Flow cytometric analysis clearly showed that the cells isolated in our study were positive for CD105 (Figure 3B), CD44 (Figure 3C) and CD29 (Figure 3D), all of which are surface markers characteristic of MSCs. Further experiments showed that the isolated cells preserved their pluripotency, as evident by differentiation into myogenic (Figure 3E, left) and adipogenic (Figure 3E, right) lineages. In addition, the human BM-MSCs attached and grew well on the GF surface, as illustrated by a representative immunostaining image (Figure 3F) in which the cells were labeled with anti- $\beta$-tubulin antibody (green) and DAPI for the cell nucleus (blue).

Then, viability of the BM-MSCs was measured using the MTT assay. Cells treated with VC were viable, and $\mathrm{VC}$ at the dose of $50 \mu \mathrm{g} / \mathrm{ml}$ enhanced cell viability (Figure 3G. As an oxidative stress inducer, $\mathrm{H}_{2} \mathrm{O}_{2}$ decreased cell viability and such suppression was significant when the concentration was higher than $0.2 \mathrm{mM}$ (Figure $3 \mathrm{H}$ ). $25 \mu \mathrm{g} / \mathrm{ml} \mathrm{VC}$ and $0.2 \mathrm{mM} \mathrm{H}_{2} \mathrm{O}_{2}$ were used in the following experiments since they caused significant changes in term of cell viability. The cytotoxicity of $0.2 \mathrm{mM} \mathrm{H}_{2} \mathrm{O}_{2}$ was significantly rescued, and the cell viability was restored to normal level by $25 \mu \mathrm{g} / \mathrm{ml} \mathrm{VC,} \mathrm{GF} \mathrm{and} \mathrm{VC} \mathrm{+} \mathrm{GF} \mathrm{(} p>0.05$, Figure 3I), strongly indicating their antioxidant effect.

\section{GF, VC and GF+VC successfully attenuated $\mathrm{H}_{2} \mathrm{O}_{2}-$ induced oxidative stress in human BM-MSCs}

Meanwhile, the effects of $\mathrm{GF}$ and $\mathrm{VC}$ on $\mathrm{H}_{2} \mathrm{O}_{2}$ induced oxidative stress were examined in human BMMSCs. $0.2 \mathrm{mM} \mathrm{H}_{2} \mathrm{O}_{2}$ induced the ROS level in the culture to about $260 \%$ of the control without treatment. The $\mathrm{H}_{2} \mathrm{O}_{2}$-induced ROS increase was attenuated by $25 \mu \mathrm{g} / \mathrm{ml}$ VC $(p<0.05)$ and GF $(p<0.05)$ (Figure 4A), while such attenuation was more pronounced to a level of $82 \%$ by the 
A

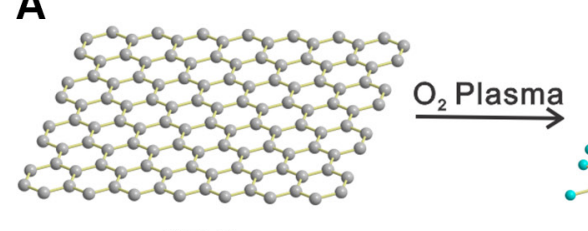

3D G

B

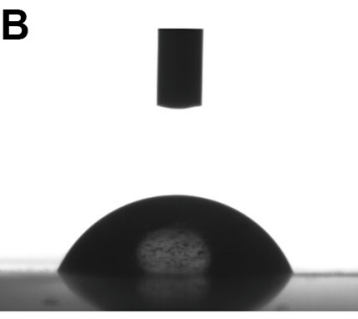

3D G

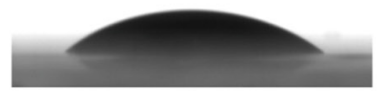

Oxidation

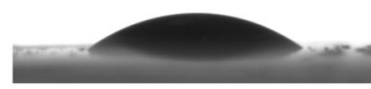

VC-3D G

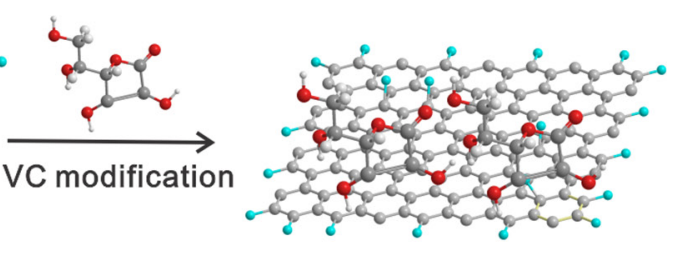

VC-3D G

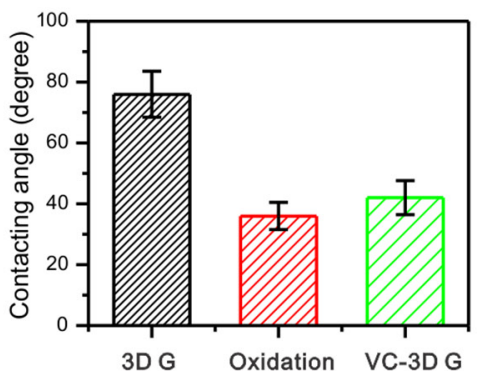

Figure 1: (A) A schematic of 3D GF treated with $\mathrm{O}_{2}$ plasma and VC modification. (B) The contact angles of 3D GF pristine, $\mathrm{O}_{2}$ plasma treated 3D G and VC modified 3D GF.
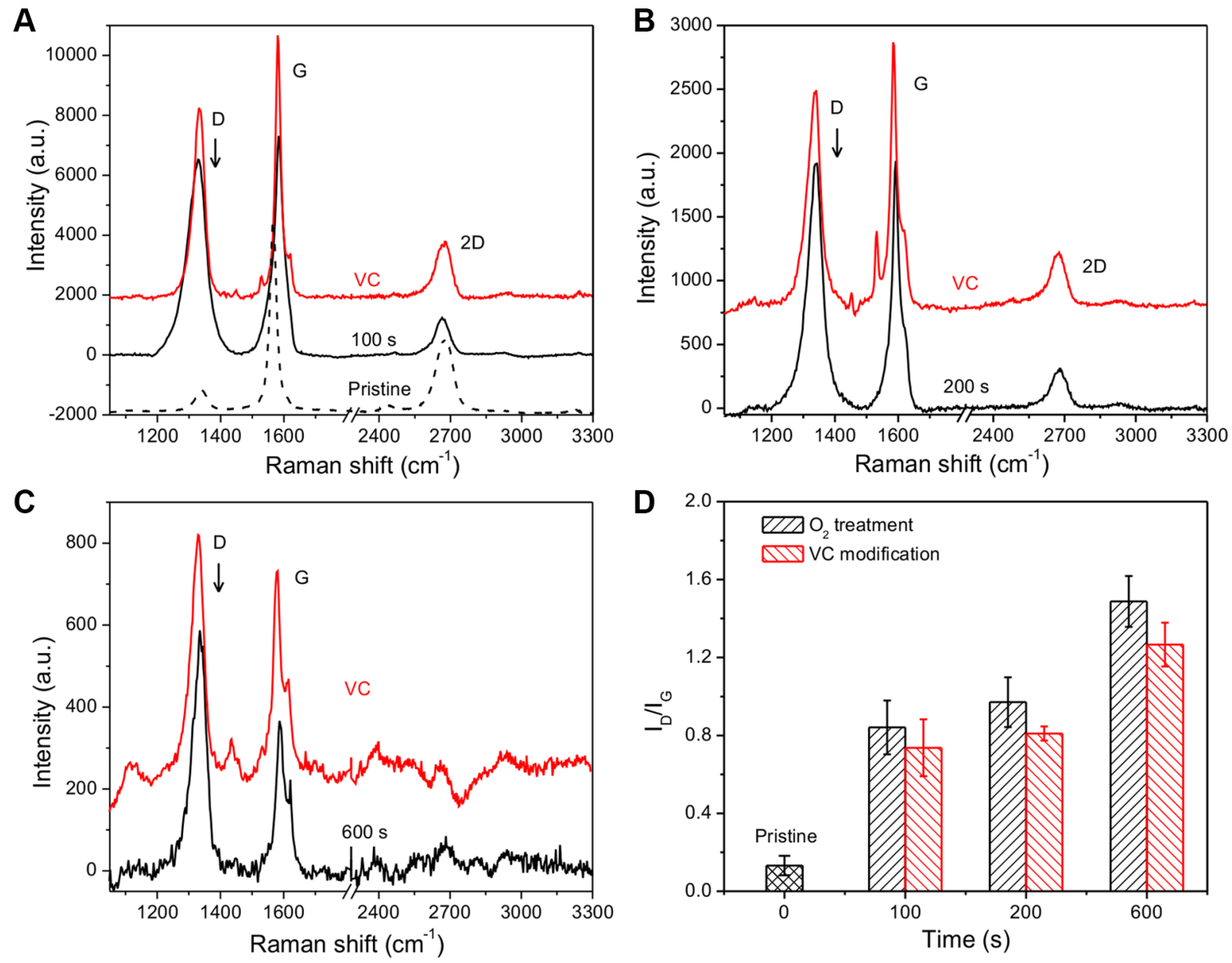

Figure 2: Raman spectra of 3D GF, $\mathrm{O}_{2}$ plasma treated 3D GF and VC modified 3D GF. The 3D GF was treated by $\mathrm{O}_{2}$ plasma for (A) $100 \mathrm{~s}$, (B) $200 \mathrm{~s}$ and (C) $600 \mathrm{~s}$. (D) The intensity ratio of D peak and G peak as a function of the exposure time to $\mathrm{O}_{2}$ plasma and $\mathrm{VC}$ modification. 
co-treatment of VC + GF (Figure 4A). In addition, changes in the endogenous non-enzymatic antioxidant glutathione (GSH) level confirmed the rescue effect of VC and GF: the GSH level was inhibited to about $48 \%$ by the treatment of $0.2 \mathrm{mM} \mathrm{H}_{2} \mathrm{O}_{2}$, which was significantly rescued by VC (25 $\mu \mathrm{g} / \mathrm{ml}, p<0.05$, Figure 4B) and GF (Figure 4B). Consistently, such rescue effect was even more pronounced in the VC + GF group (Figure 4B). Moreover, superoxide dismutase (SOD) activities confirmed that $0.2 \mathrm{mM} \mathrm{H}_{2} \mathrm{O}_{2}$ induced oxidative stress $(p<0.05)$, which was then significantly rescued by $\mathrm{VC}, \mathrm{GF}$, and $\mathrm{VC}+\mathrm{GF}$
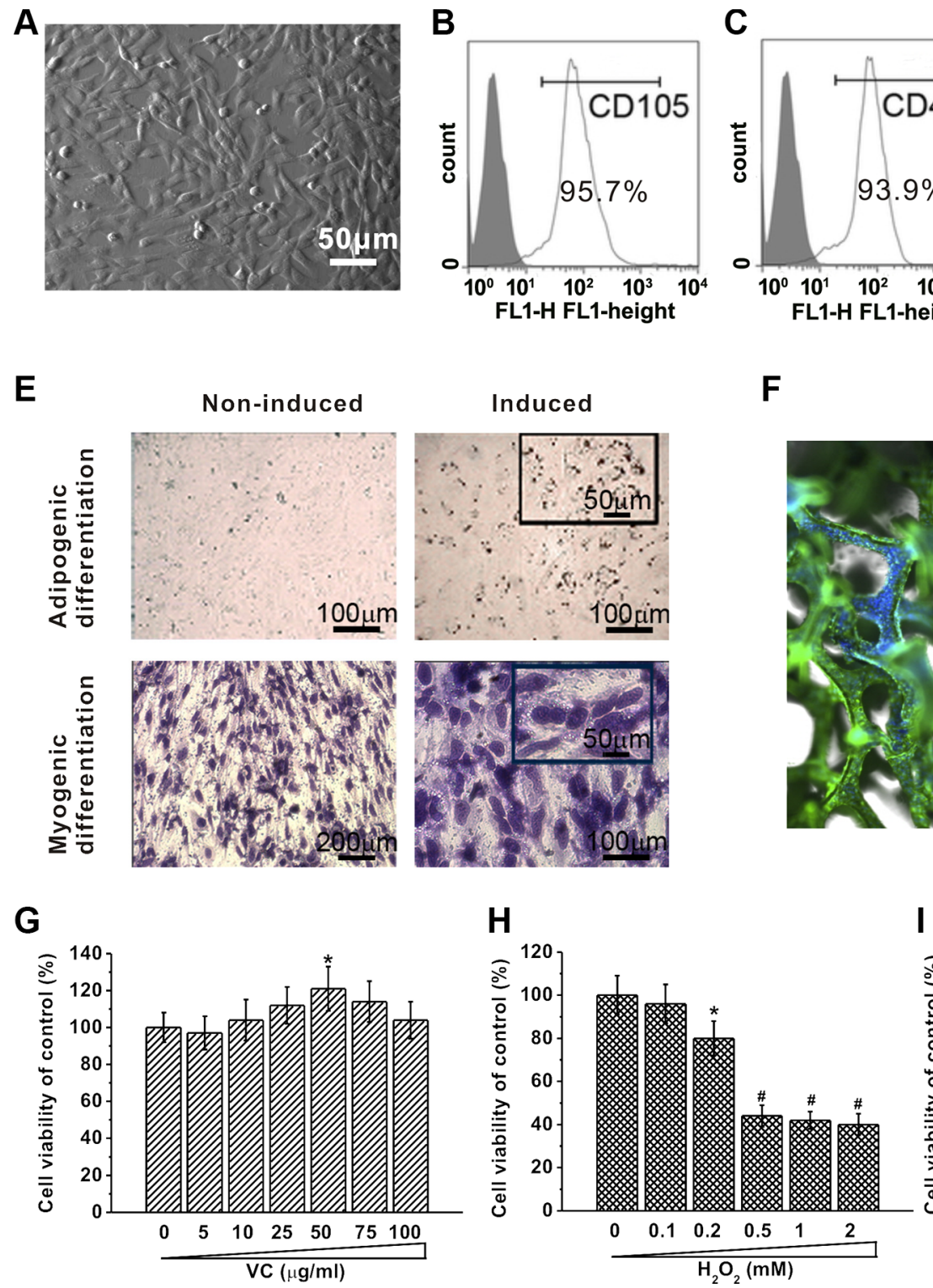

( $p<0.05$, Figure 4C). Not surprisingly, malondialdehyde (MDA) level, another marker of oxidative stress, was significantly upregulated by the treatment of $0.2 \mathrm{mM}$ $\mathrm{H}_{2} \mathrm{O}_{2}$, which was again significantly inhibited by either VC or GF, showing even more pronounced effect in the $\mathrm{VC}+\mathrm{GF}$ group (Figure 4D).

\section{Differentiation of human BM-MSCs}

Sox-2, oct-4, and nanog are stem cell markers, whose downregulation correlates with the loss of pluripotency
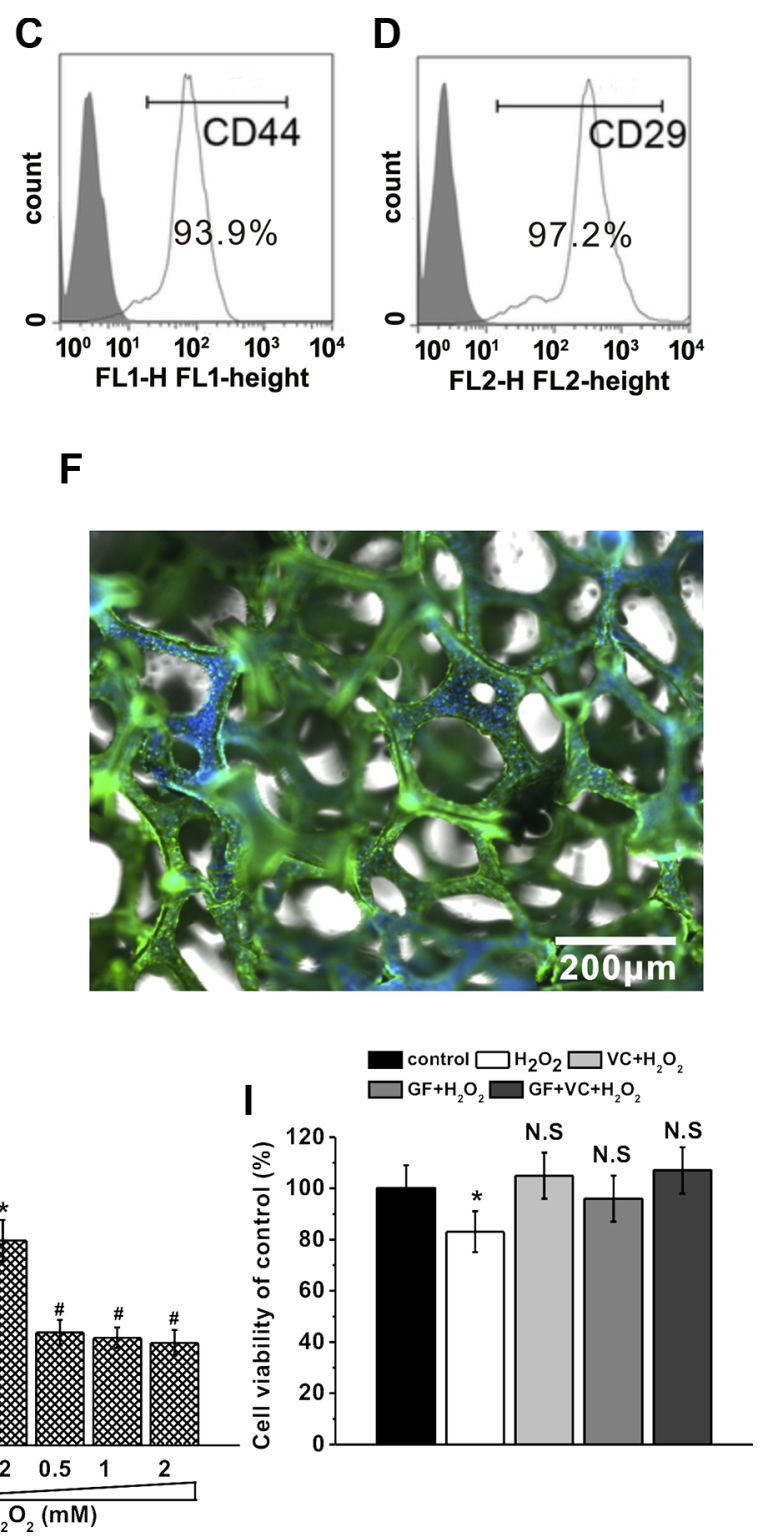

Figure 3: BM-MSCs growth under different concentrations of VC, $\mathrm{H}_{2} \mathrm{O}_{2}$ treatment or on GF substrates. (A) Representative image of BM-MSCs 5 days after seeding. (B-D) Characterization of BM-MSCs by flow cytometry. The majority of the cells are CD105, $\mathrm{CD}_{4}{ }^{+}$and $\mathrm{CD}_{29} 9^{+}$, which are typical characteristic phenotypes of BM-MSCs. (E) BM-MSC can be differentiated into adipogenic and myogenic lineages. Adipogenic differentiation was characterized by Oil Red O staining, while myogenic differentiation was evidenced by the formation of myotubes stained with crystal violet. (F) Representative image of immunostaining of BM-MSCs on GF scaffold, stained by anti- $\beta$-tubulin (green) and DAPI for nucleus (blue). Effects of different concentrations of VC (5 to $100 \mu \mathrm{g} / \mathrm{ml}, 5 \mathrm{days})(\mathbf{G})$ and $\mathrm{H}_{2} \mathrm{O}_{2}$ exposure (0.1 to $2 \mathrm{mM}, 24$ hours) $(\mathbf{H})$ on cell viability of BM-MSCs cultured for 5 days, measured by MTT assay. (I) Cell viability of $\mathrm{BM}-\mathrm{MSCs}$ in the five experimental groups. Data were presented as mean $\pm \mathrm{SEM}$. ${ }^{*} p<0.05$ vs control. 
and the beginning of subsequent differentiation steps. We examined their respective levels in the culture after different treatments during differentiation in the culture medium for osteogenic differentiation in the first 7 days. RT-PCR showed that the sox- 2 mRNA level decreased with time in the control, as the cells were being differentiated (Figure 5A). However, the reduction of the sox-2 level was inhibited after the treatment of $0.2 \mathrm{mM}$ $\mathrm{H}_{2} \mathrm{O}_{2}$ compared to the control (Figure 5A), which can be rescued by $\mathrm{VC}, \mathrm{GF}$ and $\mathrm{VC}+\mathrm{GF}$ treatments (Figure 5A). These results suggested that the $\mathrm{H}_{2} \mathrm{O}_{2}$-impaired differentiation was rescued with the application of $\mathrm{VC}$, GF and VC + GF. Similarly, such rescued differentiation in the $\mathrm{VC}, \mathrm{GF}$ and $\mathrm{VC}+\mathrm{GF}$ group was also confirmed by the changes in levels of oct-4 (Figure 5B) and nanog mRNA (Figure 5C).

\section{Osteogenesis of human BM-MSCs}

Furthermore, we investigated the osteogenesis of human BM-MSCs in the culture directly. $0.2 \mathrm{mM} \mathrm{H}_{2} \mathrm{O}_{2}$ decreased the ALP activity to approximately $42 \%$ after 8 days of differentiation (Figure 6A). Such decrease was rescued in the $\mathrm{VC}, \mathrm{GF}$ and $\mathrm{VC}+\mathrm{GF}$ treatment group
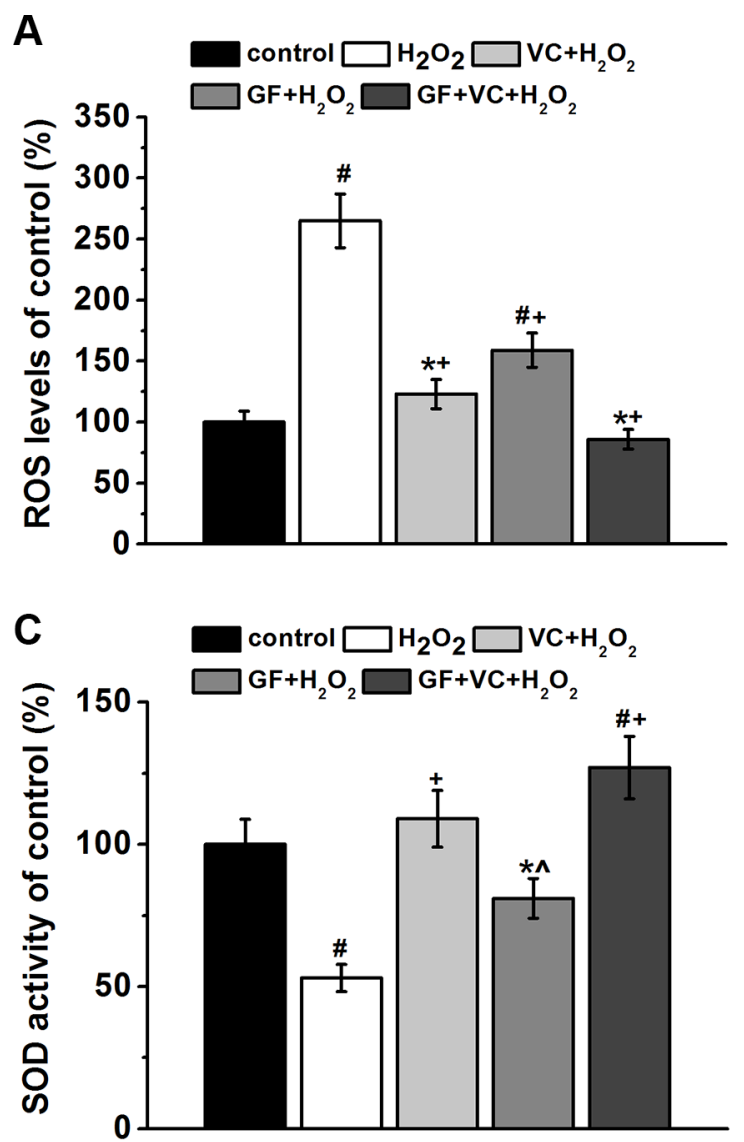

$(P<0.05$, Figure 6A). Calcium contents examined on day 16 confirmed that $0.2 \mathrm{mM} \mathrm{H}_{2} \mathrm{O}_{2}$ inhibited osteogenesis, which was also successfully restored by the application of VC, GF and VC + GF $(p<0.05)$ (Figure 6B). Of note, co-treatment of $\mathrm{VC}+\mathrm{GF}$ rescued the $\mathrm{H}_{2} \mathrm{O}_{2}$-suppressed differentiation more significantly compared to treatment of $\mathrm{VC}$ or GF alone (Figure 6A and 6B). Runx2 and Osx are two important marker genes of osteogenesis. RT-PCR revealed that $\mathrm{H}_{2} \mathrm{O}_{2}$ inhibited the transcript levels of Runx 2 and Osx on day 7 during differentiation $(p<0.05$, Figure 6C), and such inhibition was rescued by the application of VC, GF and VC $+\mathrm{GF}$ ( $p<0.05$, Figure 6C). Altogether, $\mathrm{H}_{2} \mathrm{O}_{2}$ inhibited the osteogenesis of human BM-MSCs, whereas VC, GF and VC + GF significantly restored $\mathrm{H}_{2} \mathrm{O}_{2}$-inhibited osteogenesis. In addition, the combination of $\mathrm{VC}+\mathrm{GF}$ was consistently more effective than $\mathrm{VC}$ and GF alone.

\section{The Wnt pathway was involved in the protective effects of GF and VC}

The Wnt pathway is involved in osteogenesis of MSCs (Figure 7F). Western blot analysis demonstrated that $0.2 \mathrm{mM} \mathrm{H}_{2} \mathrm{O}_{2}$ inhibited the expression of $\beta$-catenin and
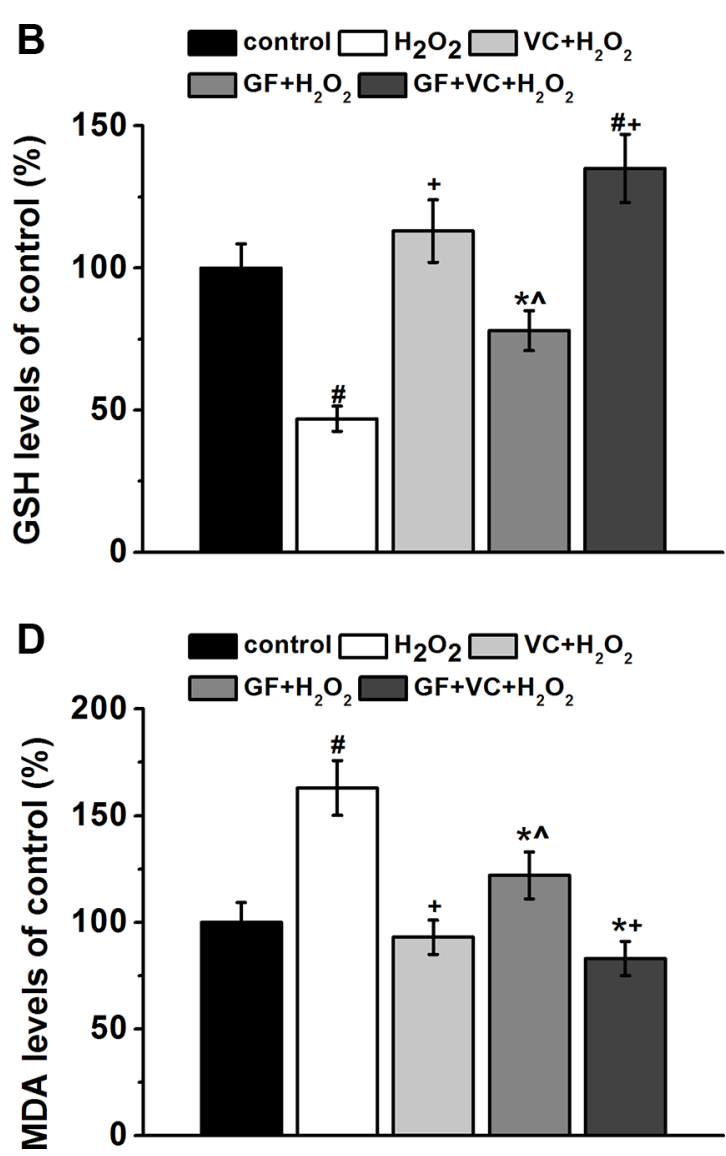

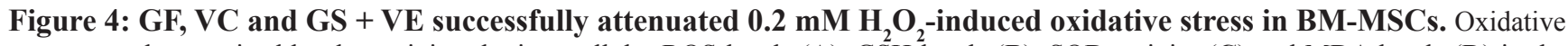
stress was characterized by determining the intracellular ROS levels (A), GSH levels (B), SOD activity (C) and MDA levels (D) in the cultures for 7 days. Data were presented as mean \pm SEM. ${ }^{*} p<0.05$ and ${ }^{*} p<0.01$ vs control, ${ }^{\wedge} p<0.05$ and ${ }^{+} p<0.01 \mathrm{vs}_{2} \mathrm{O}_{2}$ treatment group. 
cyclin D1 (Figure 7A), and such inhibition was restored by the co-application of VC, GF and VC + GF (Figure 7A). Statistical analysis from 3 independent experiments indicated the inhibition and further restoration were both significant (Figure 7B). As a gain-of-function assay, the Wnt pathway was inhibited by a specific inhibitor DKK-1 at $0.2 \mu \mathrm{g} / \mathrm{ml}$, consistent with previous study [32]. After the application of DKK-1, alkaline phosphatase (ALP) activity on day 8 was inhibited by $0.2 \mathrm{mM} \mathrm{H}_{2} \mathrm{O}_{2}$ down to about $42 \%$, as measured in a previous experiment (Figure 6A). However, ALP activities after application of VC, GF and $\mathrm{VC}+\mathrm{GF}$ were $63 \%, 51 \%$ and $72 \%$, respectively (Figure 7C). This was significantly lower than those in the absence of DKK-1, which were $124 \%, 75 \%$ and $133 \%$, respectively (Figure 6A). These above results suggested that the Wnt pathway was involved in the protective effects of $\mathrm{VC}, \mathrm{GF}$ and $\mathrm{VC}+\mathrm{GF}$ against $\mathrm{H}_{2} \mathrm{O}_{2}$-induced inhibition of osteogenic differentiation. Similarly, calcium content on day 16 was rescued by $\mathrm{VC}, \mathrm{GF}$ and $\mathrm{VC}+\mathrm{GF}$, albeit to a markedly lower extent (Figure 7D) than in the presence of Wnt pathway function (Figure 6B). This result further confirmed that the Wnt pathway was involved in the protective effects of VC, GF and VC + GF. Such involvement of the Wnt pathway was also validated by the mRNA expression levels of Runx 2 and Osx (Figure 7E).

\section{In vivo osteogenesis of MSCs under different treatment}

Furthermore, an in vivo mice model of osteogenesis was employed. A total of $1 \times 10^{6}$ human BM-MSCs were injected subcutaneously into 8 weeks old male athymic nude mice. First, calcium contents were measured 2 weeks later, which was significantly lower in oxidative stress treatment group compared to control. However, such reduced calcium content was significantly rescued by treatment of VC, GF and VC + GF under oxidative stress, with $\mathrm{VC}+\mathrm{GF}$ co-treatment displaying the most effective capability (Figure 8A). Besides, H\&E staining and quantitative analysis revealed similar phenomenon in these experimental groups, as evidenced by the restored bone formation of BM-MSCs in the presence of oxidative stress when treated by VC, GF or VC + GF (Figure 8B and 8C).

\section{DISCUSSION}

Many obstacles remain in clinic in the stem cell-based therapies, especially the local oxidative microenvironment, where transplanted MSCs undergo apoptosis. It was noted that up to $80 \%$ stem cells died in 2 days after transplantation due to the local adverse microenvironment [33]. At the same time, numerous reports demonstrated that adverse oxidative stress inhibited osteogenesis of MSCs. Therefore, antioxidants are widely applied during cell transplantation in the therapy of bone diseases, such as VC and vitamin E, etc [11, 34-37]. Nevertheless, the efficacy of antioxidants applied is usually limited by their short in vivo half-life. Hence, in the present study, we chemically linked VC onto 3D structure of GF, aiming to prolong the half-life of VC. Meanwhile, graphene and its derivatives, including GF, have emerged as a promising nanomaterial in regenerative medicine and tissue engineering since their initial report in 2004 [15], due to their excellent physical and chemical properties [38, 39]. There are numerous studies demonstrating that graphene-based nanomaterials exhibit good biocompatibility and little cytotoxicity in various cell types [38]. In our current study, we employed 3D GFs loaded with VC to promote the growth and differentiation of BM-MSCs, in order to evaluate its efficacy as stem cell therapy based on BM-MSCs. The 3D GFs exhibited excellent biocompatibility. Within 10 hours of seeding, the human BM-MSCs were able to steadily attach to the 3D GFs, with some adhered to the surfaces of culture dishes, leaving nearly no cells floating free in the culture (data not shown). Moreover, we didn't observe any cytotoxicity from 3D GFs in the cultured human BM-MSCs, which was supported by the result that GF rescued $\mathrm{H}_{2} \mathrm{O}_{2}$-impared
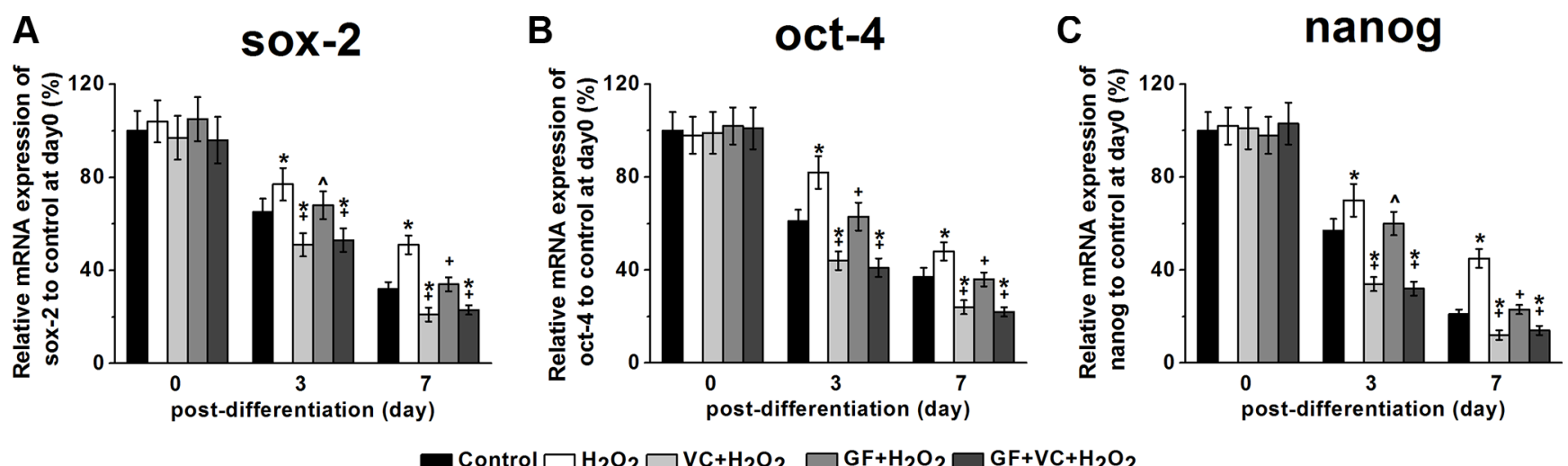

Figure 5: Sox-2 (A), oct-4 (B) and nanog (C) mRNA expressions of the MSCs in the five experimental groups during differentiation. mRNA expressions were measured by RT-PCR. The data were normalized to their corresponding control at post

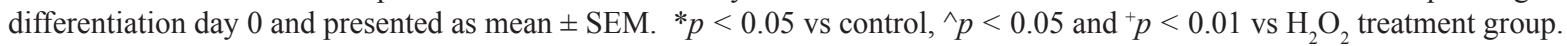


A

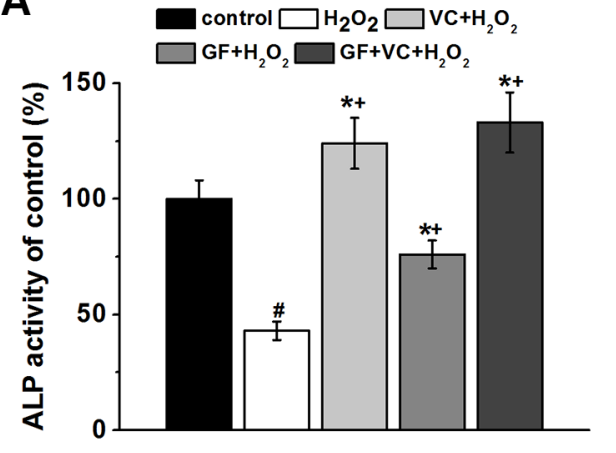

B

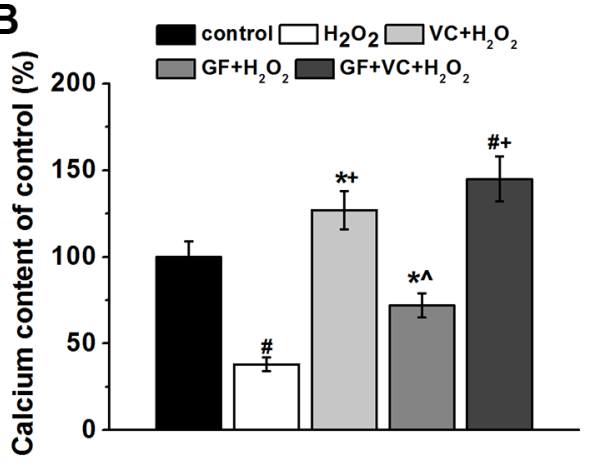

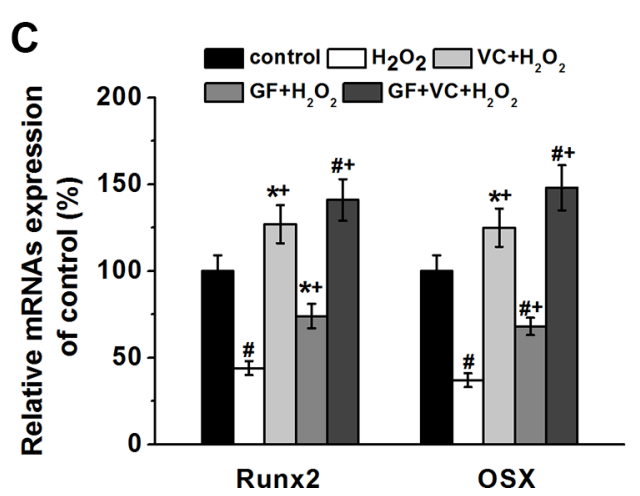

Figure 6: Both GF and VC protected against $0.2 \mathrm{mM} \mathrm{H}_{2} \mathrm{O}_{2}$-induced inhibition of osteogenic differentiation of BM-MSCs. ALP activity (A) and calcium contents (B) of the cultures of the four experimental groups normalized to control. (C) Relative mRNAs expressions of Runx2 and Osx in the four experimental groups, quantified by RT-PCR. Data were presented as mean \pm SEM.

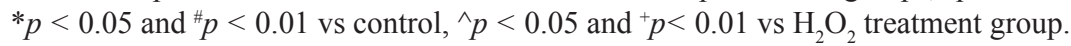

A
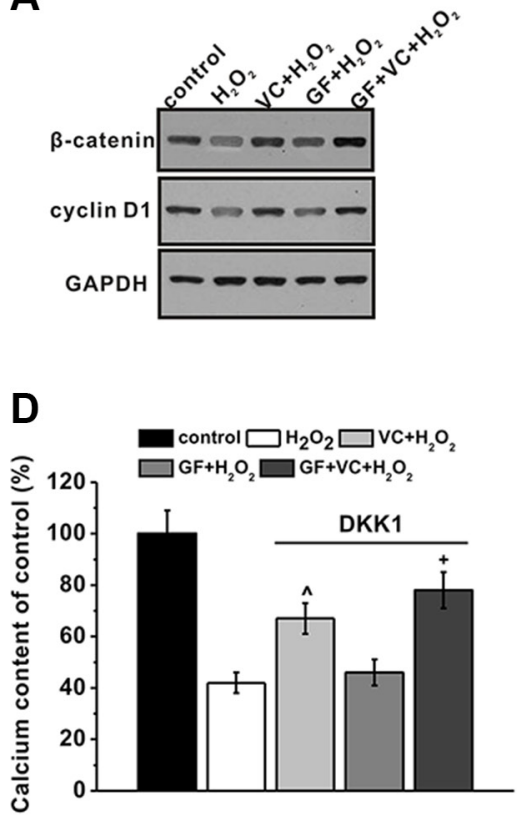

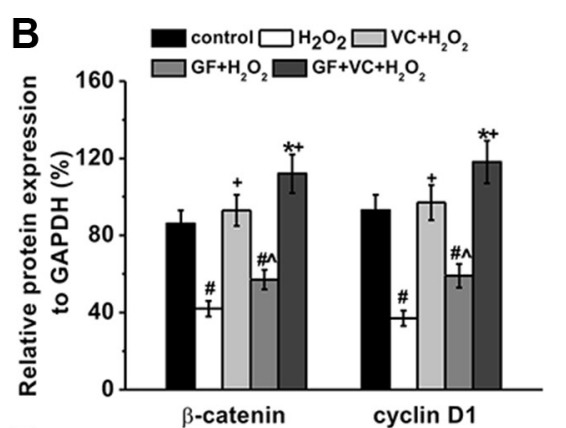

E

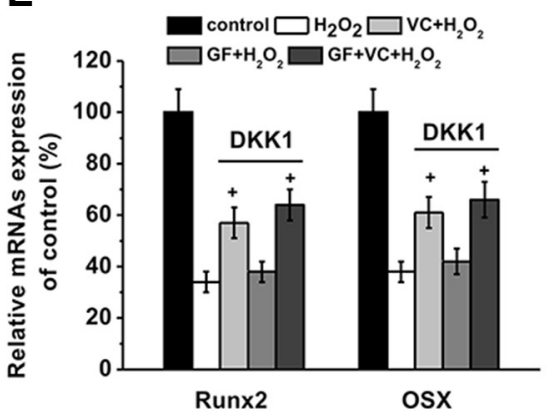

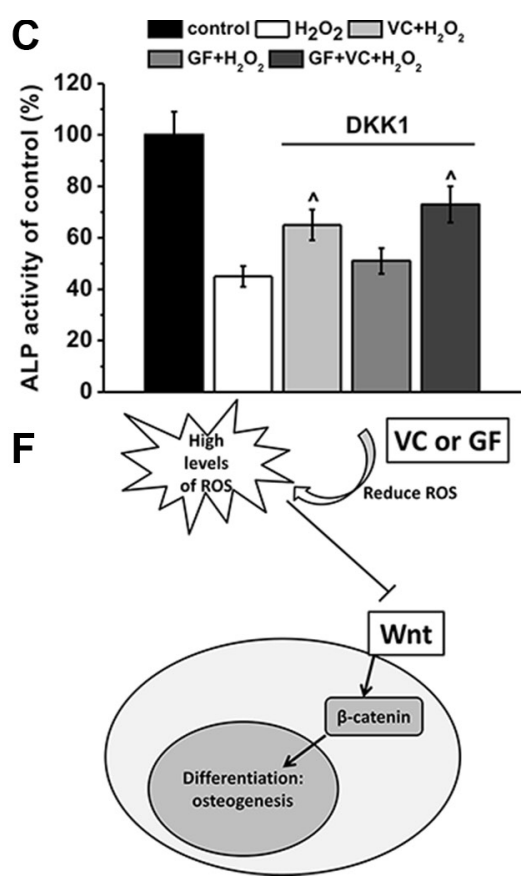

Figure 7: Wnt pathway was involved in the protective effects of GF and VC on the inhibition of osteogenic differentiation induced by $0.2 \mathrm{mM} \mathrm{H} \mathrm{H}_{2} \mathrm{O}_{2}$. (A) Western blot analysis (A) and the relative protein expression (B) of Wnt pathway-related regulators $\beta$-catenin and Cyclin D1 in the cultures of experimental groups. DKK-1, wnt pathway inhibitor, blocked the protective effects of VC or GF on the inhibition of osteogenic differentiation by $\mathrm{H}_{2} \mathrm{O}_{2}$ exposure, as evidenced by ALP activity (C), calcium contents (D) and relative mRNAs expression of Runx2 and $O s x(\mathbf{E})$. (F) A schematic picture showing the possible role of wnt signaling pathway. Data were presented as mean \pm SEM. ${ }^{*} p<0.05$ and ${ }^{*} p<0.01$ vs control, ${ }^{\wedge} p<0.05$ and ${ }^{+} p<0.01$ vs $_{2} \mathrm{O}_{2}$ treatment group. 
cell viability. These above observation is consistent with previous results, where $2 \mathrm{D}$ graphene films were found to serve as excellent interface material for other types of cells [40-42]. In the preparation of the 3D GF, chemical vapor deposition method was used, which is compatible with high-quality graphene, therefore the biological effect was not severely affected by impurities [19, 40].

Interestingly, GF itself may exhibit the capability against oxidative stress. Qiu et al. recently demonstrated the antioxidant property of graphene-based materials, which was attributed to their extreme large surface area to efficiently scavenge free radicals [18]. As the hydroxyl radicals are formed photolytically in the graphene-based materials, their reducing effect is achieved through a synergistic action of inhibition of antioxidant activity inhibition (UV absorption) and scavenging of $\mathrm{OH}$ radical. Therefore the 3D GF used in our study also works as an antioxidant nanomaterial, which further protects MSCs from oxidative stress, together with chemically linked antioxidant VC.

In our current study, we have clearly demonstrated that oxidative stress inhibited viability, differentiation and osteogenesis of human BM-MSCs in an in vitro cell culture of $\mathrm{H}_{2} \mathrm{O}_{2}$-induced oxidative stress. The application of $\mathrm{VC}, \mathrm{GF}$ and $\mathrm{VC}+\mathrm{GF}$ rescued the $\mathrm{H}_{2} \mathrm{O}_{2}$-impaired cell viability and differentiation of human BM-MSCs. Meanwhile, we found that $\mathrm{VC}, \mathrm{GF}$ and $\mathrm{VC}+\mathrm{GF}$ restored the $\mathrm{H}_{2} \mathrm{O}_{2}$-inhibited osteogenic process, as evidenced by restored calcium contents and ALP activity, as well as the mRNA levels of both $O s x$ and Runx 2 in the cultures. Furthermore, the protective effect of GF, VC and GF + VC against oxidative stress-inhibited osteogenesis was also clearly demonstrated in an in vivo mouse model of osteogenesis.

Wnt signaling pathway is reported to be implicated in the osteogenesis of MSCs. In our current study, we have shown that $\mathrm{H}_{2} \mathrm{O}_{2}$ inhibited the Wnt signaling-related regulators, such as cyclin D1 and $\beta$-catenin, and such inhibition was rescued by the application of $\mathrm{VC}, \mathrm{GF}$ and $\mathrm{VC}+\mathrm{GF}$, suggesting that Wnt signaling was involved in the $\mathrm{H}_{2} \mathrm{O}_{2}$-impaired osteogenesis, as well as in the following VC or GF-protective effect during osteogenesis. Meanwhile, when the Wnt pathway was inhibited by $0.2 \mu \mathrm{g} / \mathrm{ml} \mathrm{DKK}-1$, the rescue effect of $\mathrm{VC}$, GF and $\mathrm{VC}+\mathrm{GF}$ was noticeably lower, as evidenced by the reduced ALP activity and calcium contents in the culture, as well as the relative mRNA expressions of Runx 2 and Osx. Therefore, it can be reasoned that the Wnt pathway played an essential role in the $\mathrm{H}_{2} \mathrm{O}_{2}$-inhibited osteogenesis and in the antioxidant VC or GF-rescued osteogenesis.

Of clinical significance, we hereby clearly demonstrated that the combination of VC and GF displayed a more potent protective effect against oxidative stress than monotherapy of either VC or GF, in terms of cell viability, differentiation and osteogenesis both in vitro and in vivo. Our results may shed light on the clinical management of oxidative stress-induced bone-related diseases, and should have certain significance of reference for other oxidative
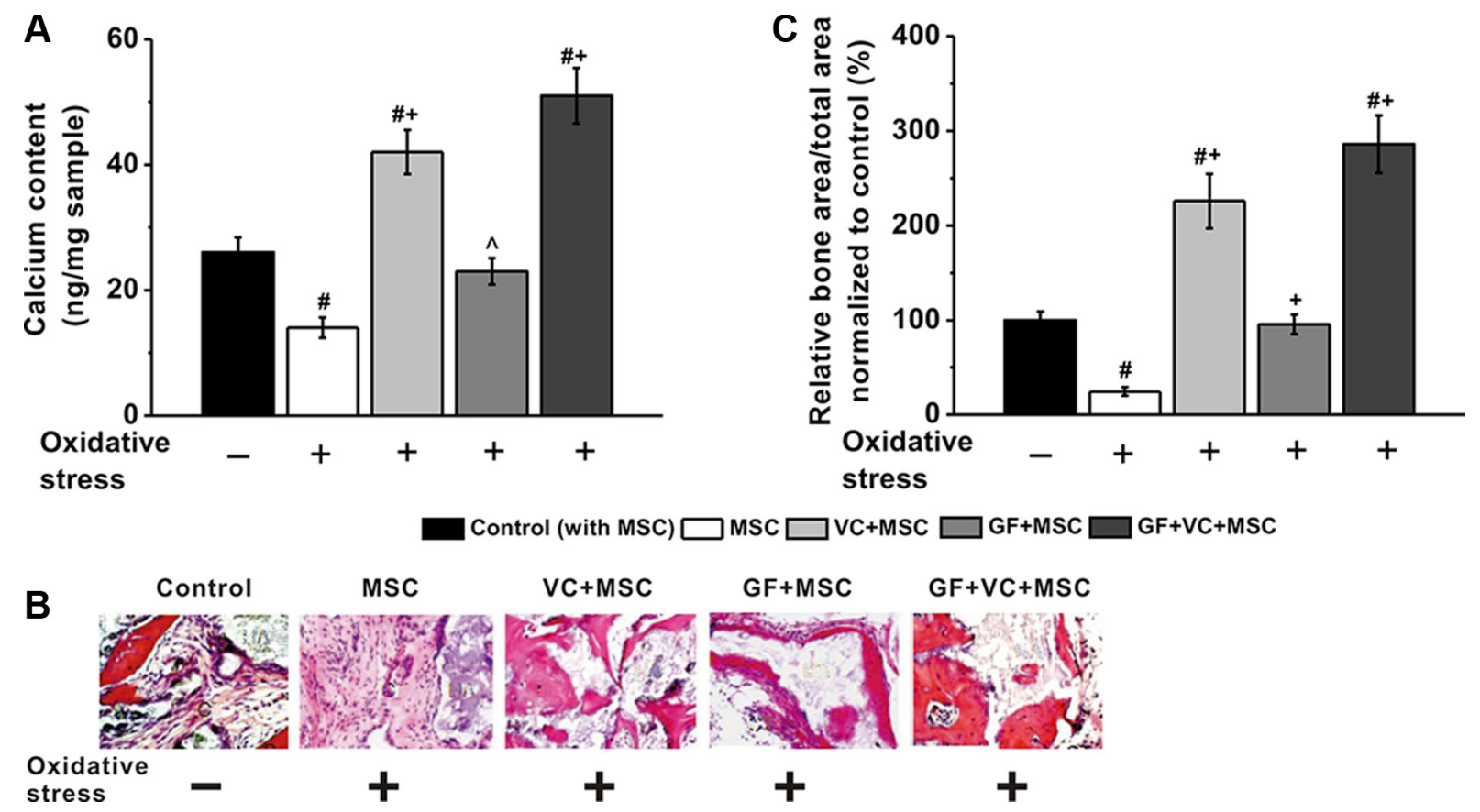

Control (with MSC)
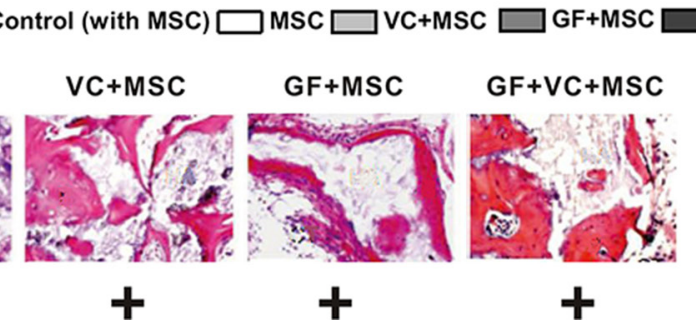

Figure 8: VC and GF facilitated in vivo osteogenesis of MSCs impaired by oxidative stress. VC, GF and co-treatment of VC and GF groups enhanced calcium contents in an in vivo nude mice model (A). (B) Representative images of H\&E staining of tissue samples in these five experimental groups. (C) Quantitative analysis of the amount of new bone formation in these groups. Data were presented as mean \pm SEM. ${ }^{*} p<0.01$ vs control mice without oxidative stress, $\wedge p<0.05$ and ${ }^{+} p<0.01$ vs mice with oxidative stress. 
stress-induced diseases. Nevertheless, more careful and systematic examinations on the biosafety of this system should be done before any further clinical use.

\section{MATERIALS AND METHODS}

\section{GF Synthesis}

GFs were synthesized according to previous reports [19-21]. In brief, the chemical vapor deposition method was employed for the synthesis of 3D GFs using Ni foams as template (Alantum Advanced Technology Materials, China). Samples were first immersed into $1.0 \mathrm{M} \mathrm{FeCl}_{3}$ solution at room temperature for at least 3 days, then were rinsed sequentially with $1.0,0.1$ and $0.01 \mathrm{M} \mathrm{HCl}$, after which samples were rinsed with running water for at least 3 days for removal of the etching agents.

\section{Characterization of GFs}

The crystallinity of GFs was characterized by Raman spectrometer lamRAM HR800 (HORIBA, France).

\section{Oxygen plasma treatment}

The oxygen plasma treatment was accomplished with a downstream inductively coupled plasma asher (DFS-200, BMR) equipped with a remote oxygen $\left(\mathrm{O}_{2}\right)$ gas. The radiofrequency power to remotely generate plasma was $100 \mathrm{~W}$ and the pressure of oxygen was 300 mTorr. After treating the graphene with oxygen plasma, Raman spectroscopy was utilized to characterize the structural changes.

\section{VC modification}

VC modification of graphene was conducted in a sealed bottle with ethanol as medium. The initial concentration of VC in ethanol was $1 \mathrm{M}$ and the $\mathrm{pH}$ value was adjusted to $9-10$ with $25 \%$ ammonia solution. The sealed bottle containing $5 \mathrm{ml} \mathrm{VC}$ solution was sonicated in water bath for $10 \mathrm{~min}$ and kept at $50^{\circ} \mathrm{C}$ for $4 \mathrm{~h}$. After that, the modified graphene was rinsed in water for six times to remove the free VC molecules.

\section{Contact angle}

The water drops were dispensed onto the surface of graphene film and then the sessile water contact angle $\theta$ was measured on a magnified image captured with a video camera (DataPhysics OCA, Germany).

\section{Human BM-MSC culture}

Human BM-MSCs were isolated and passaged according to previous reports [22, 23]. In brief, 2.0-3.0 $\mathrm{ml}$ of bone marrow aspirate were collected from the osteotomy sites of 5 adult healthy donors (24-35 age, two male and three female), who have given written and signed informed consents. The aspirate was then gently mixed with $\alpha$-minimum essential medium ( $\alpha$-MEM) to make the total volume of $10 \mathrm{ml}$, which contains $15 \%$ embryonic stem cell qualified-fetal bovine serum (ES-FBS) (Gibco, Grand Island, NY, USA), $100 \mu \mathrm{g} / \mathrm{ml}$ streptomycin, $2 \mathrm{mM}$ L-glutamine, $100 \mathrm{U} / \mathrm{ml}$ penicillin, 18\% Chang B and $2 \%$ Chang C (Irvine Scientific, Santa Ana, CA, USA). Isolated cells were then cultured in a humidified incubator at $37^{\circ} \mathrm{C}$ with $5 \% \mathrm{CO}_{2}$ for 5 days. Debris and blood were carefully removed by washing with serum-free $\alpha$-MEM. Cells were then cultured to approximately $90 \%$ confluency before being split into fresh medium at 30\% confluency. The medium was changed every other day. Cells between passages 3-5 were used for experiments.

For in vitro studies, BM-MSCs were initially seeded on the surface of GF at a density of $0.5 \times 10^{6}$, which was placed on the bottom of the 96 well cell culture plates (Corning, NY, USA). After a gentle shake, the drop with BM-MSCs spread into the entire GF scaffold. Then, a final volume of $200 \mu \mathrm{l}$ culture medium was added. For control and $\mathrm{H}_{2} \mathrm{O}_{2}$ groups, cells were also seeded in the 96 well cell culture plates at the same density.

\section{3-(4, 5-dimethylthiazol-2-yl)-2, 5-diphenyl tetrazolium bromide (MTT) assay}

MTT assay (Sigma, St. Louis, MO) was employed in the study to assess cell viability. For $\mathrm{H}_{2} \mathrm{O}_{2}$ treatment, cells were incubated with $\mathrm{H}_{2} \mathrm{O}_{2}$ at different concentrations for the first $24 \mathrm{~h}$ before changing to fresh culture medium without $\mathrm{H}_{2} \mathrm{O}_{2}$. For $\mathrm{VC}$ treatment, $\mathrm{VC}$ was present in the culture medium throughout cell culture.

\section{Osteoblast differentiation}

Induction of osteogenic differentiation of human BM-MSCs was performed using $10 \mathrm{nM}$ dexamethasone (Sigma). To examine the osteogenesis, cells were seeded into a 96-well plate at approximately $80 \%$ confluency. The culture medium was replaced after $24 \mathrm{~h}$ with DMEM osteogenic medium, containing 10\% FBS, $60 \mathrm{mM}$ ascorbic acid, $10 \mathrm{mM}$ glyceraldehydes 3 phosphate and $10 \mathrm{nM}$ dexamethasone. The osteogenic medium was changed every other day.

\section{Flow cytometry}

Flow cytometry followed routine protocols. Cells were stained with antibodies specific for CD105, CD29 and CD44, then cells were acquired and analyzed by a BD FACS Canto using the FACS Diva software (BD Bioscience, Bedford, MA, USA). Antibodies used in the study were as follows: CD105-FITC (MCA1557FT, Serotec, Oxford, UK), CD44-FITC (MCA643FA, 
Serotec), and CD29-FITC (MCA1949FT, Serotec). Fluorochrome-conjugated mouse isotype control IgG (Serotec) was used as negative labeling control.

\section{Measurement of oxidative stress}

ROS, GSH and MDA levels, SOD activity were all determined using commercial detection kits (Jiancheng Biotech, Nanjing, China) following the manufacturer's manuals. Briefly, GSH activity was measured by the reaction of 5.50-dithiobis-2-nitrobenzoic acid (DTNB) with GSH, the product of which can be read at $412 \mathrm{~nm}$ using a spectrophotometer. Binding of MDA with thiobarbituric acid results in a chromogenic complex that can be detected at $532 \mathrm{~nm}$. SOD activity can be measured spectrophotometrically based on inhibition reaction of NADPH-phenazinemethosulphate-nitroblue tetrazolium formazan, as enzyme reaction can be detected by recording the absorption at $560 \mathrm{~nm}$. Intracellular ROS level was measured using the $2^{\prime}, 7^{\prime}$-dichlorofluorescin diacetate (DCFH-DA) probe (Sigma) in a detection kit. The ROS level was measured as the absorbance at $525 \mathrm{~nm}$ recorded with a spectrometer.

\section{ALP activity assay}

Human BM-MSCs were cultured in osteogenesis medium, which was replaced every other day. After 8 days the cells were washed twice with TB buffer $(20 \mathrm{mM}$ Tris, $150 \mathrm{mM} \mathrm{NaCl}, \mathrm{pH} 7.5$ ), and then lysed with $100 \mu \mathrm{l} 0.1 \%$ Triton in TB buffer. After centrifugation at $12,000 \mathrm{rpm}$ at $4^{\circ} \mathrm{C}$ for $20 \mathrm{~min}, 45 \mu \mathrm{l}$ supernatant was incubated with $100 \mu \mathrm{l}$ ALP substrate p-nitrophenyl phosphatate liquid substrate system (Promega, Madison, WI, USA) for 20 min at $37^{\circ} \mathrm{C}$, and the absorbance at $405 \mathrm{~nm}$ was measured using a spectrophotometer . ALP activity was normalized to total protein.

\section{Calcium content assay}

Human BM-MSCs were cultured in osteogenesis medium with treatments as indicated for 24 days. The medium was changed every other day. On day 24 calcium content in the culture was determined using Calcium Assay kit (Genzyme Diagnostics, Charlottetown, PE, Canada) according to the manufacturer's manual. The absorbance was measured at $650 \mathrm{~nm}$. All samples were measured in triplicates and compared to the standard cure for calcium calibration, and the calcium content was normalized to cell number.

\section{Quantitative real-time reverse transcription polymerase chain reaction (RT-PCR)}

Total cellular RNA was prepared using the RNeasy kit (Qiagen, Valencia, CA), and cDNA was then synthesized using the SuperScript RT III (Invitrogen, Pleasanton, CA), following manufacturer's instructions. RT-PCR was then performed following routine protocols. The primers used for the amplification of target genes were shown in supplementary Table S1. Relative expression levels were normalized to $\beta$-actin.

\section{Immunofluorescence}

The cultures were washed twice in PBS buffer, fixed using $4 \%$ paraformaldehyde in PBS for $40 \mathrm{~min}$, then blocked and permeabilized in PBS containing $2 \%$ BSA and $0.1 \%$ triton X-100 for 80 min. Cells were immunostained using primary antibody ( $\beta$-tubulin, Sigma) for $90 \mathrm{~min}$, washed three times with PBS, followed by incubating with secondary antibody (Invitrogen, USA) for another $70 \mathrm{~min}$. The nucleus was stained with DAPI (Sigma).

\section{Differentiation of MSCs into myogenic and adipogenic lineages}

Human BM-MSCs were cultured for approximately 4 weeks in NM supplemented with $5 \mu \mathrm{g} / \mathrm{ml}$ insulin and $10 \mathrm{nM}$ dexamethasone to induce adipogenic differentiation. The cells were then fixed using $4 \%$ paraformaldehyde in PBS at room temperature for $1 \mathrm{~h}$, and stained using Oil Red O (Sigma) solution to confirm their identity. Similarly, cells were incubated with DMEM-H containing 10\% FBS, $50 \mu \mathrm{M}$ hydrocortisone (Pfizer Inc, NY, USA), $5 \%$ horse serum (Sigma) and $0.1 \mu \mathrm{M}$ dexamethasone (Sigma) in order to induce myogenesis. Myogenesis differentiation was observed with crystal violet staining of the formed myotubes.

\section{Western blot analysis}

After treatment, BM-MSCs were washed with PBS for 3 times, followed by incubation with lysis buffer according routine protocols. Primary antibodies used in the study were as follows: cyclin D1 (\#2926, Cell Signaling); $\beta$-catenin (\#13727, Cell Signaling, Boston, MA, USA); GAPDH (\#G9545, Sigma). Western blot was quantified using the Image-Proplus 5.0 software (Media Cybernetics Inc., Silver Spring, MD, USA).

\section{In vivo osteogenesis of BM-MSCs}

All animal experiments in the study were performed in compliance with the Guide for the Care and Use of Laboratory Animals of NIH. A total of $1 \times 10^{6}$ human BM-MSCs was injected subcutaneously into 8 weeks old male athymic nude mice. After the mice were treated with general anesthesia, small incisions were made in the skin on the back of the mice to form subcutaneous pouches, into which the human BM-MSCs were injected. 
The skin incisions were then closed using 4-0 nylons. For oxidative stress treatment, the mice were fed with high-fat diet containing $2 \%$ cholesterol, $20 \%$ coconut oil and $0.125 \%$ bile salts, as established previously. [24] VC was orally administrated at $50 \mu \mathrm{g} / \mathrm{Kg}$ body weight. GF or $\mathrm{VC}+\mathrm{GF}$ was implanted subcutaneously right before BMMSC transplantation. To measure the calcium contents of in vivo implanted specimens, individual samples were deparaffinized, dried at $95^{\circ} \mathrm{C}$ for $1 \mathrm{~h}$, weighed, and then decalcified in $1 \mathrm{ml}$ Calci-clear Rapid solution. Calcium content of the supernatants was measured using the Methylxylene blue method. H\&E staining followed a routine procedure and the histological sections were analyzed by ImageJ software.

\section{Statistical analysis}

All values were are calculated as mean \pm S.E.M. All experiments were independently repeated at least 3 times. Student's $t$-test was conducted for comparison between two groups, and $P<0.05$ was deemed statistically significant unless otherwise noted.

\section{ACKNOWLEDGMENTS}

None.

\section{CONFLICTS OF INTEREST}

The authors declare no competing financial interest.

\section{FUNDING}

This work was supported by the National Natural Science Foundation of China (No. 81472110, 81572155); Shanghai Municipal Natural Science Foundation (No. 14ZR1431800), the Interdisciplinary Program of Shanghai Jiao Tong University (No. YG2014MS22), Three-year action plan (2014-2016) of Shanghai's Development Acceleration in Traditional Chinese Medicine (No. ZY3CCCX-3-3044).

\section{REFERENCES}

1. Wauquier F, Leotoing L, Coxam V, Guicheux J, Wittrant Y. Oxidative stress in bone remodelling and disease. Trends Mol Med. 2009; 15:468-77. doi: 10.1016/j. molmed.2009.08.004.

2. Redlich K, Smolen JS. Inflammatory bone loss: pathogenesis and therapeutic intervention. Nat Rev Drug Discov. 2012; 11:234-50. doi: 10.1038/nrd3669.

3. Loeser RF, Gandhi U, Long DL, Yin W, Chubinskaya S. Aging and oxidative stress reduce the response of human articular chondrocytes to insulin-like growth factor 1 and osteogenic protein 1. Arthritis Rheumatol. 2014; 66:2201-9. doi: 10.1002/art.38641.
4. Manolagas SC. From estrogen-centric to aging and oxidative stress: a revised perspective of the pathogenesis of osteoporosis. Endocr Rev. 2010; 31:266-300. doi: 10.1210/ er.2009-0024.

5. Oni OO. Early histological and ultrastructural changes in medullary fracture callus. J Bone Joint Surg Am. 1992; 74:633-4.

6. Brighton CT, Hunt RM. Early histologic and ultrastructural changes in microvessels of periosteal callus. J Orthop Trauma. 1997; 11:244-53.

7. Pittenger MF, Mackay AM, Beck SC, Jaiswal RK, Douglas R, Mosca JD, Moorman MA, Simonetti DW, Craig S, Marshak DR. Multilineage potential of adult human mesenchymal stem cells. Science. 1999; 284:143-7.

8. Beyer Nardi N, da Silva Meirelles L. Mesenchymal stem cells: isolation, in vitro expansion and characterization. Handbook of experimental pharmacology. 2006; 249-82.

9. Digirolamo CM, Stokes D, Colter D, Phinney DG, Class R, Prockop DJ. Propagation and senescence of human marrow stromal cells in culture: a simple colony-forming assay identifies samples with the greatest potential to propagate and differentiate. Br J Haematol. 1999; 107:275-81.

10. Horwitz EM, Prockop DJ, Fitzpatrick LA, Koo WW, Gordon PL, Neel M, Sussman M, Orchard P, Marx JC, Pyeritz RE, Brenner MK. Transplantability and therapeutic effects of bone marrow-derived mesenchymal cells in children with osteogenesis imperfecta. Nat Med. 1999; 5:309-13. doi: 10.1038/6529.

11. Esteban MA, Wang T, Qin B, Yang J, Qin D, Cai J, Li W, Weng Z, Chen J, Ni S, Chen K, Li Y, Liu X, et al. Vitamin C enhances the generation of mouse and human induced pluripotent stem cells. Cell Stem Cell. 2010; 6:71-9. doi: 10.1016/j.stem.2009.12.001.

12. Gao Y, Han Z, Li Q, Wu Y, Shi X, Ai Z, Du J, Li W, Guo Z, Zhang Y. Vitamin $C$ induces a pluripotent state in mouse embryonic stem cells by modulating microRNA expression. FEBS J. 2015; 282:685-99. doi: 10.1111/febs.13173.

13. Guo P, Zeng JJ, Zhou N. A novel experimental study on the fabrication and biological characteristics of canine bone marrow mesenchymal stem cells sheet using vitamin C. Scanning. 2015; 37:42-8. doi: 10.1002/sca.21177.

14. Wei C, Liu X, Tao J, Wu R, Zhang P, Bian Y, Li Y, Fang F, Zhang Y. Effects of vitamin $\mathrm{C}$ on characteristics retaining of in vitro-cultured mouse adipose-derived stem cells. In Vitro Cell Dev Biol Anim. 2014; 50:75-86. doi: 10.1007/ s11626-013-9673-6.

15. Novoselov KS, Geim AK, Morozov SV, Jiang D, Zhang Y, Dubonos SV, Grigorieva IV, Firsov AA. Electric field effect in atomically thin carbon films. Science. 2004; 306:666-9. doi: 10.1126/science.1102896.

16. Arya N, Arora A, Vasu KS, Sood AK, Katti DS. Combination of single walled carbon nanotubes/graphene oxide with paclitaxel: a reactive oxygen species mediated synergism for treatment of lung cancer. Nanoscale. 2013; 5:2818-29. doi: 10.1039/c3nr33190c. 
17. Park J, Kim B, Han J, Oh J, Park S, Ryu S, Jung S, Shin JY, Lee BS, Hong BH, Choi D, Kim BS. Graphene oxide flakes as a cellular adhesive: prevention of reactive oxygen species mediated death of implanted cells for cardiac repair. ACS Nano. 2015; 9:4987-99. doi: 10.1021/nn507149w.

18. Qiu Y, Wang Z, Owens AC, Kulaots I, Chen Y, Kane AB, Hurt RH. Antioxidant chemistry of graphene-based materials and its role in oxidation protection technology. Nanoscale. 2014; 6:11744-55. doi: 10.1039/c4nr03275f.

19. Ekiz OO, Urel M, Guner H, Mizrak AK, Dana A. Reversible electrical reduction and oxidation of graphene oxide. ACS Nano. 2011; 5:2475-82. doi: 10.1021/nn1014215.

20. Dua V, Surwade SP, Ammu S, Agnihotra SR, Jain S, Roberts KE, Park S, Ruoff RS, Manohar SK. All-Organic Vapor Sensor Using Inkjet-Printed Reduced Graphene Oxide. Angewandte Chemie International Edition. 2010; 49:2154-7. doi: 10.1002/anie.200905089.

21. Fernández-Merino MJ, Guardia L, Paredes JI, VillarRodil S, Solís-Fernández P, Martínez-Alonso A, Tascón JMD. Vitamin C Is an Ideal Substitute for Hydrazine in the Reduction of Graphene Oxide Suspensions. The Journal of Physical Chemistry C. 2010; 114:6426-32. doi: 10.1021/ jp100603h.

22. Gao J, Liu F, Liu Y, Ma N, Wang Z, Zhang X. EnvironmentFriendly Method To Produce Graphene That Employs Vitamin C and Amino Acid. Chemistry of Materials. 2010; 22:2213-8. doi: 10.1021/cm902635j.

23. He Q, Sudibya HG, Yin Z, Wu S, Li H, Boey F, Huang W, Chen P, Zhang H. (2010). Centimeter-Long and LargeScale Micropatterns of Reduced Graphene Oxide Films: Fabrication and Sensing Applications. ACS Nano: American Chemical Society). 3201-8.

24. Frank O, Dresselhaus MS, Kalbac M. Raman Spectroscopy and in Situ Raman Spectroelectrochemistry of Isotopically Engineered Graphene Systems. Accounts of Chemical Research. 2015; 48:111-8. doi: 10.1021/ar500384p.

25. Xiao N, Dong X, Song L, Liu D, Tay Y, Wu S, Li L-J, Zhao Y, Yu T, Zhang H, Huang W, Hng HH, Ajayan PM, et al. Enhanced Thermopower of Graphene Films with Oxygen Plasma Treatment. ACS Nano. 2011; 5:2749-55. doi: 10.1021/nn2001849.

26. Liu M, Li Y, Yang ST. Effects of naringin on the proliferation and osteogenic differentiation of human amniotic fluid-derived stem cells. J Tissue Eng Regen Med. 2014. doi: 10.1002/term.1911.

27. Rodriguez-Porcel M, Gheysens O, Paulmurugan R, Chen IY, Peterson KM, Willmann JK, Wu JC, Zhu X, Lerman LO, Gambhir SS. Antioxidants improve early survival of cardiomyoblasts after transplantation to the myocardium. Mol Imaging Biol. 2010; 12:325-34. doi: 10.1007/s11307-009-0274-4.

28. Chung TL, Brena RM, Kolle G, Grimmond SM, Berman BP, Laird PW, Pera MF, Wolvetang EJ. Vitamin C promotes widespread yet specific DNA demethylation of the epigenome in human embryonic stem cells. Stem Cells. 2010; 28:1848-55. doi: 10.1002/stem.493.

29. Geng S, Zhou S, Bi Z, Glowacki J. Vitamin D metabolism in human bone marrow stromal (mesenchymal stem) cells. Metabolism. 2013; 62:768-77. doi: 10.1016/j. metabol.2013.01.003.

30. Gigante A, Torcianti M, Boldrini E, Manzotti S, Falcone G, Greco F, Mattioli-Belmonte M. Vitamin K and D association stimulates in vitro osteoblast differentiation of fracture site derived human mesenchymal stem cells. J Biol Regul Homeost Agents. 2008; 22:35-44.

31. Gupta A, Leong DT, Bai HF, Singh SB, Lim TC, Hutmacher DW. Osteo-maturation of adipose-derived stem cells required the combined action of vitamin D3, beta-glycerophosphate, and ascorbic acid. Biochem Biophys Res Commun. 2007; 362:17-24. doi: 10.1016/j. bbrc.2007.07.112.

32. Pinto AM, Goncalves IC, Magalhaes FD. Graphenebased materials biocompatibility: a review. Colloids Surf B Biointerfaces. 2013; 111:188-202. doi: 10.1016/j. colsurfb.2013.05.022.

33. Sanchez VC, Jachak A, Hurt RH, Kane AB. Biological interactions of graphene-family nanomaterials: an interdisciplinary review. Chem Res Toxicol. 2012; 25: 15-34. doi: 10.1021/tx200339h.

34. Park SY, Park J, Sim SH, Sung MG, Kim KS, Hong BH, Hong S. Enhanced differentiation of human neural stem cells into neurons on graphene. Adv Mater. 2011; 23: H2637. doi: 10.1002/adma.201101503.

35. Li N, Zhang X, Song Q, Su R, Zhang Q, Kong T, Liu L, Jin G, Tang M, Cheng G. The promotion of neurite sprouting and outgrowth of mouse hippocampal cells in culture by graphene substrates. Biomaterials. 2011; 32: 374-82. doi: 10.1016/j.biomaterials.2011.08.065.

36. Wang Y, Lee WC, Manga KK, Ang PK, Lu J, Liu YP, Lim CT, Loh KP. Fluorinated graphene for promoting neuro-induction of stem cells. Adv Mater. 2012; 24: 4285-90. doi: 10.1002/adma.201200846.

37. Li X, Cai W, An J, Kim S, Nah J, Yang D, Piner R, Velamakanni A, Jung I, Tutuc E, Banerjee SK, Colombo L, Ruoff RS. Large-area synthesis of high-quality and uniform graphene films on copper foils. Science. 2009 ; 324:1312-4. doi: 10.1126/science.1171245.

38. Chen Z, Ren W, Gao L, Liu B, Pei S, Cheng HM. Threedimensional flexible and conductive interconnected graphene networks grown by chemical vapour deposition. Nat Mater. 2011; 10:424-8. doi: 10.1038/nmat3001.

39. Li N, Zhang Q, Gao S, Song Q, Huang R, Wang L, Liu L, Dai J, Tang M, Cheng G. Three-dimensional graphene foam as a biocompatible and conductive scaffold for neural stem cells. Sci Rep. 2013; 3:1604. doi: 10.1038/srep01604.

40. Kosmacheva SM, Danilkovich NN, Shchepen AV, Ignatenko SI, Potapnev MP. Effect of platelet releasate on osteogenic differentiation of human mesenchymal bone 
marrow stem cells. Bull Exp Biol Med. 2014; 156:560-5. doi: 10.1007/s10517-014-2396-1.

41. Stanko P, Kaiserova K, Altanerova V, Altaner C. Comparison of human mesenchymal stem cells derived from dental pulp, bone marrow, adipose tissue, and umbilical cord tissue by gene expression. Biomed Pap
Med Fac Univ Palacky Olomouc Czech Repub. 2014; 158 : 373-7. doi: 10.5507/bp.2013.078.

42. Vijayakumar RS, Surya D, Nalini N. Antioxidant efficacy of black pepper (Piper nigrum L.) and piperine in rats with high fat diet induced oxidative stress. Redox Rep. 2004; 9:105-10. doi: 10.1179/135100004225004742. 